\title{
Operation and Maintenance in Solar Plants: Eight study cases
}

\author{
Ana P. Talayero ${ }^{1}$, J. J. Melero ${ }^{2}$, AndrésLlombart ${ }^{1}$, Adrián Casado ${ }^{2}$ \\ ${ }^{1}$ Fundación CIRCE, Zaragoza Spain \\ C/Mariano Esquillor Gómez 15, -Zaragoza 50018 (Spain) \\ Phone+0034976761863 talayero@fcirce.es; llombart@fcirce.es; \\ ${ }^{2}$ University of Zaragoza, Zaragoza Spain \\ C/Mariano Esquillor Gómez, -Zaragoza 50018 (Spain) \\ Phone+0034976762402 melero@unizar.es; casado@unizar.es
}

\begin{abstract}
The use of solar photovoltaic generation is growing up nowadays. New developments have been achieved lowering the prices of the modules and their installation. Nevertheless, the operation and maintenance of these plants still needs improvements in order to enhance their efficiency and economic balance.
\end{abstract}

This paper presents a detailed analysis of eight photovoltaic (PV) plants revealing improvements on the monitoring system and the maintenance procedures.

The common failures in PV plants have been established and their losses have been estimated. A correct diagnostic method using good information and monitoring systems could have reduced the losses.

\section{Key words}

PV Solar plants, Efficiency, Availability and Predictive maintenance.

\section{Introduction}

During the last years the photovoltaic energy is increasing at a rate higher than $20 \%$, mainly due to the Asian market [1]. Europe with a lower growth has developed policies such as "Directive 2009/28/EC of the European Parliament” [1], and “Climate action 2014” [2] with the objective of reaching in 2030 a share of $27 \%$ of renewable consumption. Due to this situation, it is expected the solar energy to be a relevant part in the energy mix around the world[3].

To assure this target, it is necessary to improve the R\&D in several fields, such as power forecasting, materials and operation and maintenance[3] allowing the PV energy to be more competitive.

The maintenance is defined as the set of actions focused on the preservation of the PV plant in good operating conditions avoiding its degradation. A good maintenance increases the availability and improves the efficiency of a PV plant. Maintenance strategies use to be classified into three categories, corrective maintenance, preventive maintenance and predictive maintenance. Corrective maintenance is applied when a failure is detected; it is unplanned, and with a high cost, because in almost all cases it is associated to shortages in the power generation, and even damages in important components of the generation plant. Preventive maintenance is based on maintaining a certain efficiency level in the plant with programmed interventions in order to avoid failures and to keep the components health at a certain service level. Finally, predictive maintenance is based on the knowledge of the health of the plant in order to predict or anticipate possible failures and make the intervention before they occur; this is usually achieved with a monitoring system and 'ad-hoc' algorithms applied to the critical variables of the plant.

Based on the findings of this study, current maintenance strategies have a high corrective component with some preventive actions. Predictive maintenance is not yet introduced in PV plants.

\section{Background}

The maintenance of PV plants has been studied in some papers. In [4] and [5] a review of the factors affecting the power generation is presented. The most common problems are listed and a good maintenance guideline is proposed. In [6] it is explained how to detect some faults through the use of detection measures like: techniques of visual inspection, electrical measurements, and thermography. In [7] electroluminiscency and ultra violet (UV) fluorescenceare introduced to detect hot spots and defects in lamination or small breaks.

The climatology, mainly the temperature, humidity and ultraviolet rays, has an influence in the failure typology, and there are several studies about these fact, [5], [8], [9], [10],[11], [12] and[13].

Other studies are focused in finding the relationship between the origin of the failure with the manufacture issues such as welding, fatigue, [14], [15], [16]and [17]. 
There are also studies regarding the efficiency improvement of the plants. Some of them look on the material of the cells to get better efficiency[18],[19] or how to enhance inverters [20]. Others, study the influence of the dirtiness over the efficiency[21], [22], even the affection of the biological agents [23], and of course there are several studies about the degradation of the solar panels [24], [25].

All the aforementioned studies present improvements in the maintenance techniques but all of them required additional instrumentation as none used the SCADA system of the plant (when present) as a helping tool for the maintenance tasks and for improving the plant efficiency. Moreover, to the authors knowledge, a detailed analysis considering the benefits obtained with the efficiency improvements and the needed investments and extra operation costs is not yet found in the literature.

This paper present a study of eight different PV plants installed in Spain analyzing:

- How they are monitored, operated and maintained.

- The most common production faults.

- The lack of production due to system and component faults.

- $\quad$ The SCADA system.

The objective is to demonstrate:

- The lack of information in most of the PV plants.

- The suitability of the performance monitoring (using SCADA data) for the detection of production losses.

\section{Description of the plants and its monitoring control system}

Eight photovoltaic plants were chosen, trying to represent the variety of PV plants installed. In this selection low power plants, as the rooftop plants, have been excluded because any study on them is not economically justified. Their main characteristics are summarized in Table 1

Table 1. Characteristic of the studied plants

\begin{tabular}{|c|c|c|c|c|}
\cline { 2 - 5 } \multicolumn{1}{c|}{} & Size & Cell & $\begin{array}{c}\text { Tracking } \\
\text { system }\end{array}$ & Maintenance \\
\hline PV1 & $1-5 \mathrm{MW}$ & Polycristaline & No & $\begin{array}{c}\text { Mainly } \\
\text { Corrective }\end{array}$ \\
\hline PV2 & $1-5 \mathrm{MW}$ & Polycristaline & No & $\begin{array}{c}\text { Mainly } \\
\text { Corrective }\end{array}$ \\
\hline PV3 & $1-5 \mathrm{MW}$ & Monocristaline & No & $\begin{array}{c}\text { Preventive- } \\
\text { Corrective }\end{array}$ \\
\hline PV4 & $>10 \mathrm{MW}$ & Polycristaline & $\begin{array}{c}1 \text { horizontal } \\
\text { axis, E-W } \\
\text { movement }\end{array}$ & $\begin{array}{c}\text { Preventive- } \\
\text { Corrective }\end{array}$ \\
\hline PV5 & $5-10 \mathrm{MW}$ & Polycristaline & 2 axis, tower & Corrective \\
\hline PV6 & $1-5 \mathrm{MW}$ & Polycristaline & 2 axis, tower & Corrective \\
\hline PV7 & $1-5 \mathrm{MW}$ & Polycristaline & 2 axis, tower & Corrective \\
\hline PV8 & $5-10 \mathrm{MW}$ & Polycristaline & 2 axis, tower & Corrective \\
\hline
\end{tabular}

When reviewing the information of the plants, the first fact found is the lack of information in their SCADA systems. This conditions the way to study them. Plants are sorted in four groups according to the available information, as it is shown in Table 2. In all cases, some information is lacking. There are two plants with information about the power production and the radiation in the data logger. There are two other plants with information of the inverter, so that it is possible to know the voltage and current before and after the conversion and also the operating temperature and alarms. Three other plants registered information of the inverter, but there were not temperature values. Finally, the last one is a plant without any information.

Despite of the lack of information, it is important to mention that when a variable is measured, its availability is high, close to $100 \%$ [26].

Table 2 shows the available variables for the different identified cases.

Table 2. Available row data

\begin{tabular}{|l|c|c|c|c|}
\cline { 2 - 5 } \multicolumn{1}{l|}{} & Type 1 & Type 2 & Type 3 & Type 4 \\
\hline Radiation & & $\mathbf{X}$ & & \\
\hline Ambient temperature & & & & \\
\hline Wind speed & & & $\mathbf{X}$ & \\
\hline Tracking position & - & & $\mathbf{X}$ & \\
\hline Module temperature & & & & \\
\hline Vdc & $\mathbf{X}$ & & $\mathbf{X}$ & \\
\hline Idc & $\mathbf{X}$ & & $\mathbf{X}$ & \\
\hline Vac & $\mathbf{X}$ & & $\mathbf{X}$ & \\
\hline Iac & $\mathbf{X}$ & & $\mathbf{X}$ & \\
\hline Pdc & $\mathbf{X}$ & & & \\
\hline Pac & $\mathbf{X}$ & $\mathbf{X}$ & & \\
\hline Inverter temperature & $\mathbf{X}$ & & & \\
\hline Inverter Alarms & $\mathbf{X}$ & & & \\
\hline
\end{tabular}

So, a clear conclusion from a first quick review of the available data is that there are a high number of plants with a lack of monitoring information. This is a problem in the operation and maintenance, because it increases the financial risk [27] and limits possible improvements. It is also difficult to develop performance monitoring methodologies and the analysis of the state of the plant.

\section{Applied methodology}

The performance ratio (PR) is a percentage that describes the relationship between current and theoretical energy output of the PV plant. It is one of the most important ratios to evaluate the efficiency, because it is independent of the location of the plant. A value close to $100 \%$ means that the plant is running well, but a deviation in this value indicates possible failures in the plant.

To estimate the PR it is necessary to know the radiation, the size in square meters and the efficiency of the 
modules and the inverter in order to calculate the theoretical power production of the plant. This means that only when the radiation is measured, it is possible to estimate correctly this factor. In our study cases there are only two plants, the type 2 plants, in which it is possible to estimate this factor.

If there is no radiation data, the efficiency can be estimated as a relationship between the power production and the maximum available production. This maximum production is estimated as the power production and the lack of production. So for this parameter it is necessary to estimate power losses when there is sun and the plant is fully or partially stopped.

When radiation data is available, a historical relation between the radiation and the production can be obtained as reference. In this case, losses are estimated as the difference between the power historical values and the real power. In Figure 1, the historical reference is shown in black; blue points represent every power production point and red points are moments with lack of power production. The losses are the difference between every red point and the reference line.

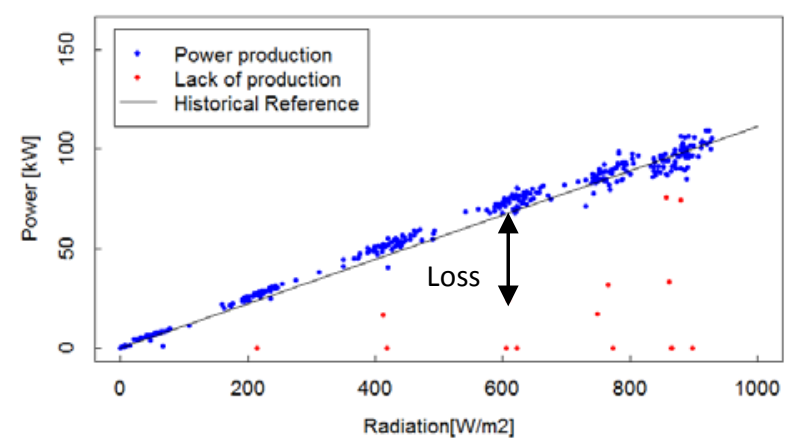

Figure 1. Historical reference, power and lack of power

When there are no radiation measurements, other modules or lines can be used as a reference to estimate the losses, such as it is mentioned in [5] and [28].Their relation is estimated with a cross correlation. When a failure affects to the whole plant, it is no possible to estimate the losses.

PR factor and efficiency factor are similar in values because both define if the PV plant is working well. They can show slightly different values, because efficiency is a factor adapted to the location and the operating conditions of the plant. If the historical reference is good enough, it is even better than the PR which it is estimated according to manufacture parameters defined in ideal conditions.

Other factor to analyze the production is the Solar Equivalent Hours, which is defined as the relationship between the energy production and the installed power. This parameter is important and useful when the nominal power of the installed modules in the same plant is different, and also to compare different generation plants.
Table 3, shows the summary of the results of the studied plants. PV Plant number 8was not possible to be analyzed because there is no information.

Table 3. Summary of the results

\begin{tabular}{|c|c|c|c|}
\cline { 2 - 4 } \multicolumn{1}{c|}{} & PR & Efficiency & SEH \\
\hline PV1 & - & $97.84 \%$ & 1492 \\
\hline PV2 & - & $98.40 \%$ & 1614 \\
\hline PV3 & $86.20 \%$ & $99.60 \%$ & 1496 \\
\hline PV4 & $85.57 \%$ & $98.89 \%$ & 1752 \\
\hline PV5 & - & $92.74 \%$ & 2030 \\
\hline PV6 & - & $92.87 \%$ & 2032 \\
\hline PV7 & - & $92.45 \%$ & 2034 \\
\hline PV8 & - & - & - \\
\hline
\end{tabular}

These parameters inform if the plant is working well or not, but do not determinate the causes of a failure. To do this it is necessary the knowledge and study of the alarms of the plant and to analyze other signals as temperatures, currents, voltages, ...

\section{Classification of the production losses}

In this section three common failure modes are presented. The power losses have been estimated in all of them, including a description of how a good management can improve the efficiency.

Case 1. Power losses caused by vegetation.

In this case it had been planned to cut the grass in fixed dates. But the rain and the hot weather of that year made the vegetation grow before than expected. The shade of the vegetation limited the power production in the panels and the Equivalent Hours of the affected lines decreased.

In Figure 2, it is shown the Equivalent Hours of two lines of the same plant in the same period, one is affected by the vegetation and the other is not affected. The reduction due to the vegetation is around half Equivalent Hour per day, so the reduction of the operating time with this condition is critical.

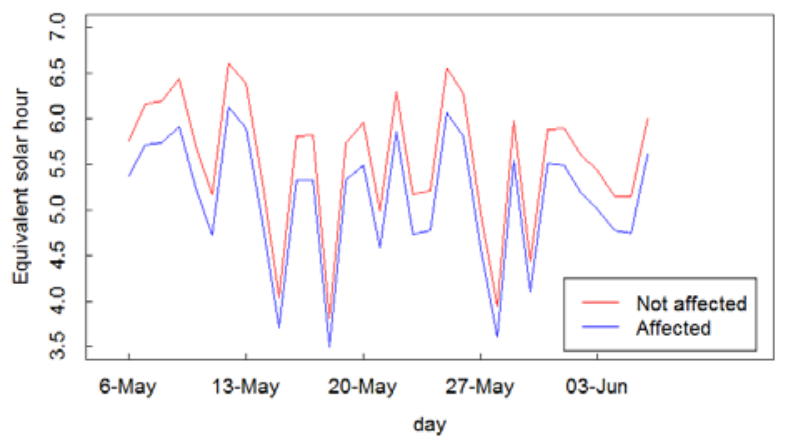

Figure 2.Vegetation growing effect

In this study case the total losses estimated for a year have been 20 Equivalent Solar Hours (ESH), what means $1.5 \%$ production loss per year and line affected. 
Depending on the number of modules affected, those losses could be high so, it is important a quick and good diagnosis in order to solve the problem as soon as possible.

\section{Case 2. Inverter failure.}

The inverter is one of the main components of a PV plant. A failure in the inverter means a shortage in the production of a part of the plant.

In this case study it has been detected a failure in the inverter, and losses have also been estimated. It is important to notice, that before the inverter failure, it was observed that the power went down and the number of alarms rose. In Figure 3, it is shown the output in Equivalent Hours of two different inverters during a period, where one of them broke. The figure shows that the production was already lower before the break.

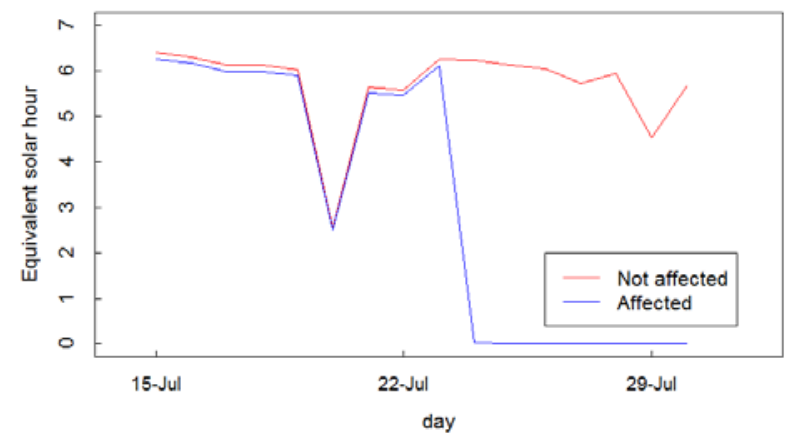

Figure 3. Inverter break

There is also an increment of errors due to over voltages before the failure, as can be seen in Figure 4.

The lack of production by this fault is $9 \%$, in the inverted affected.

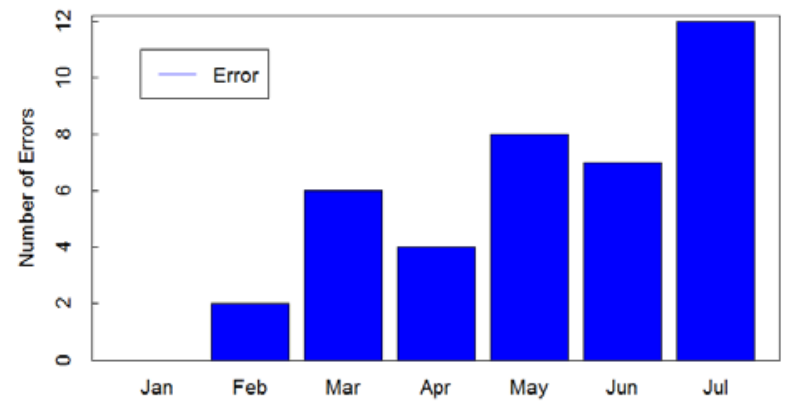

Figure 4.Failure frequency

This kind of failure is difficult to avoid, but it is possible to reduce its effect if it is detected with some anticipation and corrected before it occurs.

\section{Case 3. Tracking system failure}

The last case study has been focused in the tracking system, another critical part in some kind of PV plants.

It is common that one or even more tracking systems are misaligned in a plant. Figure 5, shows a sample of five tower-inverters; all of them except the number 2 are misaligned. The dashed horizontal line represents the value that they should have in a correct operating status.

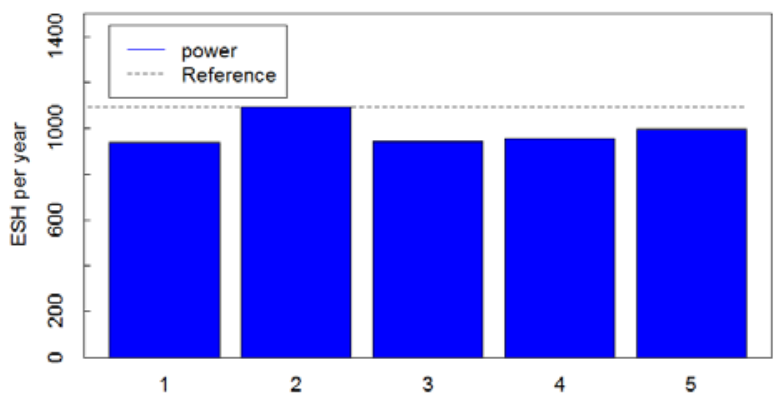

Figure 5. Failures in the tracking system

In this plant, more than half of the tower inverters have been misaligned during a part of the year. It is worth mentioning that this effect is important when there is misalignment in a huge number of track towers in the plant. A small number of misaligned track towers of even small misalignments may be negligible in terms of total power losses.

The power estimation losses have been $6.7 \%$ in a year for the studied plant. Nevertheless, this value depends on the number of affected tracking systems, the duration of the error, and even the month when the affection occurs.

The measurement and control of the efficiency and the plant production make easy to detect the misalignment soon and correct it. The availability of more information would also make possible to find a relation between breaks and external factors as wind speed, ambient temperature or humidity.

Table 4 collects the information about the complete dataset, referred to the sensor network, needed for the application of an integral predictive maintenance strategy, since this paper is focused on the first steps of the maintenance plan (data compilation and analysis). Nowadays, it is possible to collect all this information with existing commercial equipment, but it is not common to find it installed on photovoltaic plants.

Table 4. Dataset for an integral predictive maintenance

\begin{tabular}{|c|c|c|}
\hline Meteo & DC side & AC side \\
\hline Irradiation & \multicolumn{2}{|c|}{ Inverter failures } \\
\hline Wind speed & \multicolumn{2}{|c|}{ Inverter temperature } \\
\hline $\begin{array}{c}\text { Ambient } \\
\text { temperature }\end{array}$ & Voltages & Voltages \\
\hline Humidity & String currents & Currents \\
\hline \multirow{2}{*}{$\begin{array}{c}\text { Module } \\
\text { temperature }\end{array}$} & Frequency \\
\cline { 2 - 3 } & $\begin{array}{c}\text { Tracking } \\
\text { position }\end{array}$ & Power Factor \\
\cline { 2 - 3 }
\end{tabular}

The complexity and reliability of the predictive model will depend on the dataset diversity, meaning that the model can be adapted according to the available dataset. 
But it is necessary to define the minimum set of parameters that allows the application. Based on the results, this set is composed by:

- Plane of Array Irradiation,

- Module temperature and

- $\quad$ DC and AC Output Power.

\section{Conclusions}

This paper presents a review of the Operation and Maintenance of eight PV plants showing that using only available information, it is possible to estimate general parameters as PR, efficiency or Equivalent hours and calculate losses. The knowledge of these parameters in time makes possible to decrease the lack of production, improving the efficiency of the plants.

Three cases have been presented where there is a loss of production due to different failures. Losses caused by those failures have been estimated, showing that they are significant and can be reduced with the analysis of the available information. Besides that, using more information makes possible to be more effective in the detection, and even to include predictive models to prevent failures, and better plan the maintenance.

\section{References}

[1] "Home: SolarPower Europe.” [Online]. Available: http://www.solarpowereurope.org/home/. [Accessed: 06-Aug-2017].

[2] “Search - European Commission.” [Online]. Available:

http://ec.europa.eu/geninfo/query/index.do?filterNum= 0\&queryText=Climate+action+2014\&summary=sum mary\&more_options_source=global\&more_options_d ate $=* \&$ more_options_date_from $=\&$ more_options_dat e_to=\&more_options_language=es\&more_options_f_f ormats $=* \&$ swlang $=$ es. [Accessed: 06-Aug-2017].

[3] UNEF, “Informe Anual 2016,” Unión Española Fotovoltaica, p. 100, 2016.

[4] A. Woyte and S. Goy, 11 - Large grid-connected photovoltaic power plants: Best practices for the design and operation of large photovoltaic power plants. Elsevier Ltd., 2017.

[5] R. Iea-pvps, Assessment of Photovoltaic Module Failures in the Field. 2017.

[6] N. M. Pearsall, "6 - Prediction and measurement of photovoltaic system energy yield,” Perform. Photovolt. Syst., pp. 183-208, 2017.

[7] J. I. Van M??lken, U. A. Yusufo??lu, A. Safiei, H. Windgassen, R. Khandelwal, T. M. Pletzer, and H. Kurza, "Impact of micro-cracks on the degradation of solar cell performance based on two-diode model parameters," Energy Procedia, vol. 27, pp. 167-172, 2012.

[8] S. A. S. Eldin, M. S. Abd-Elhady, and H. A. Kandil, "Feasibility of solar tracking systems for PV panels in hot and cold regions," Renew. Energy, vol. 85, pp. 228-233, 2015.
[9] N. Gökmen, W. Hu, P. Hou, Z. Chen, D. Sera, and S. Spataru, "Investigation of wind speed cooling effect on PV panels in windy locations,” Renew. Energy, vol. 90, pp. 283-290, 2016.

[10] B. P. Rand, J. Genoe, P. Heremans, and J. Poortmans, "Solar Cells Utilizing Small Molecular Weight Organic Semiconductors,” Prog. Photovolt Res. Appl., vol. 15, no. February 2013, pp. 659-676, 2007.

[11] D. C. Miller, E. Annigoni, A. Ballion, J. G. Bokria, L. S. Bruckman, D. M. Burns, X. Chen, J. Feng, R. H. French, S. Fowler, C. C. Honeker, M. D. Kempe, H. Khonkar, M. Kohl, L. E. Perret-Aebi, N. H. Phillips, K. P. Scott, F. Sculati-Meillaud, and J. H.

Wohlgemuth, "Degradation in PV encapsulant strength of attachment: An interlaboratory study towards a climate-specific test," Conf. Rec. IEEE Photovolt. Spec. Conf., vol. 2016-Novem, no. August, pp. 95100, 2016.

[12] J. Polo, W. G. Fernandez-Neira, and M. C. AlonsoGarc??a, "On the use of reference modules as irradiance sensor for monitoring and modelling rooftop PV systems,” Renew. Energy, vol. 106, pp. 186-191, 2017.

[13] S. Workshop and P. Reliability, "IEC Quality Assurance Task Group 5 : UV , Temperature , and Humidity $\bullet$ Motivation : Goals and activities for QA TG5 Some details of the $\mathrm{E}$ a experiment :

Encapsulation discoloration Encapsulation adhesion • Timeline for TG5,” pp. 0-13, 2014.

[14] Y. Eguchi, G. Ramu, S. V Lokanath, M. Yamamichi, and S. Kurtz, "Requirements for Quality Management System for PV Module Manufacturing,” pp. 35743579, 2014.

[15] E. E. Van Dyk, J. B. Chamel, and A. R. Gxasheka, "Investigation of delamination in an edge-defined film-fed growth photovoltaic module,” Sol. Energy Mater. Sol. Cells, vol. 88, no. 4, pp. 403-411, 2005.

[16] T. Takashima, J. Yamaguchi, K. Otani, T. Oozeki, K. Kato, and M. Ishida, "Experimental studies of fault location in PV module strings," Sol. Energy Mater. Sol. Cells, vol. 93, no. 6-7, pp. 1079-1082, 2009.

[17] N. Bosco, T. J. Silverman, and S. Kurtz, “Climate specific thermomechanical fatigue of flat plate photovoltaic module solder joints," Microelectron. Reliab., vol. 62, pp. 124-129, 2016.

[18] J. C. Sánchez Barroso, N. Barth, J. P. M. Correia, S. Ahzi, and M. A. Khaleel, "A computational analysis of coupled thermal and electrical behavior of PV panels," Sol. Energy Mater. Sol. Cells, vol. 148, pp. 73-86, 2016.

[19] D. Jordan and S. Kurtz, Photovoltaic module stability and reliability. Elsevier Ltd., 2016.

[20] S. Islam, A. Woyte, R. Belmans, P. J. M. Heskes, and P. M. Rooij, "Investigating performance, reliability and safety parameters of photovoltaic module inverter: Test results and compliances with the standards," Renew. Energy, vol. 31, no. 8, pp. 1157-1181, 2006.

[21] M. Saidan, A. G. Albaali, E. Alasis, and J. K. Kaldellis, "Experimental study on the effect of dust 
deposition on solar photovoltaic panels in desert environment," Renew. Energy, vol. 92, pp. 499-505, 2016.

[22] A. Sayyah, M. N. Horenstein, and M. K. Mazumder, "Energy yield loss caused by dust deposition on photovoltaic panels," Sol. Energy, vol. 107, pp. 576604, 2014.

[23] S. Noack-Schönmann, O. Spagin, K.-P. Gründer, M. Breithaupt, A. Günter, B. Muschik, and A. A.

Gorbushina, "Sub-aerial biofilms as blockers of solar radiation: spectral properties as tools to characterise material-relevant microbial growth,” Int. Biodeterior. Biodegradation, vol. 86, pp. 286-293, 2014.

[24] D. C. Jordan, T. J. Silverman, J. H. Wohlgemuth, S. R. Kurtz, and K. T. VanSant, "Photovoltaic failure and degradation modes,” Prog. Photovoltaics Res. Appl., vol. 25, no. 4, pp. 318-326, Apr. 2017.

[25] D. C. Jordan, S. R. Kurtz, K. VanSant, and J.

Newmiller, "Compendium of photovoltaic degradation rates,” Prog. Photovoltaics Res. Appl., vol. 24, no. 7, pp. 978-989, Jul. 2016.

[26] A. Woyte, M. Richter, D. Moser, M. Green, S. Mau, and H. G. Beyer, Analytical Monitoring of Gridconnected Photovoltaic Systems, vol. 13, no. 2. 2014.

[27] R. Iea-pvps, Technical Assumptions Used in PV Financial Models Review of Current Practices and Recommendations. 2017.

[28] N. Gupta, R. Garg, and P. Kumar, "Sensitivity and reliability models of a PV system connected to grid," Renew. Sustain. Energy Rev., vol. 69, no. March 2016 pp. 188-196, 2017. 